\title{
Loneliness and Cyberloafing in the Time of COVID-19: A Psychological Perspective
}

Murat Çolak* ${ }^{*+}$ https://orcid.org/0000-0002-6135-1694

Cemile Çetin ${ }^{\star *}$ https://orcid.org/0000-0002-6659-4855

*Jagiellonian University, Cracow, Poland. Email: colak@muratcolak.com

**Dokuz Eylul University, Izmir, Turkey. Email: cemilegurcay@gmail.com

Abstract

Background. The COVID-19 pandemic, which has affected the entire world, has driven countries into economic, social, and political uncertainty and has forced quite significant changes, especially in areas such as health, work, education, and social security. Social changes that are occurring as a result of the crisis include the restructuring of businesses and working styles and the shaping of work life along the new-normal axis. Many psychosocial risks such as conflict management, organisational relationships, communications problems, job satisfaction, stress, productivity, and performance are being redefined as the nature of jobs, job descriptions, employee competence, and ways of working are being recreated for a virtual environment. The importance of concepts related to work psychology such as loneliness, cyberloafing, digital mobbing, emotional resilience, psychological resilience, compassion, self-compassion, conscious awareness, design of habits, coping with loneliness, and coping with crisis is becoming apparent.

Research aims. The aim of this study is to examine cyberloafing and loneliness with its changing structure in terms of work psychology. In addition, the researchers and their results on cyberloafing and loneliness are discussed in terms of both sociodemographic factors and some variables of work life.

Methodology. The research method of critical analysis of literature on the subject of cyberloafing and loneliness was applied in this study. Common findings of secondary research were used in terms of work psychology.

Findings. The concepts of loneliness and cyberloafing, which have been evaluated in relation to different sociodemographic and work-life factors and whose mutual relations have been the subject of a very limited number of studies, are examined more intensively in the context of personal and organisational factors applicable to the technology-intensive future.

Keywords

COVID-19, work psychology, cyberloafing, loneliness.

\section{INTRODUCTION}

Since ancient times, millions of people have died from the plague, flu, cholera, and other infections caused by bacteria, viruses, or other microorganisms. Advances in medicine have largely eliminated this condition through vaccines and other solutions. Today, however, modern societies face a new kind of outbreak: behavioural outbreaks (Jeste et al., 2020, p. 553). One of these outbreaks is defined as loneliness and the other as cyberloafing.

According to British historian Alberti, the term loneliness did not appear in English until 1800. Loneliness is also described as being alone without sadness. According to Alberti, since the early nineteenth century, industrialisation has reduced social connectedness, and the concept of loneliness emerged. This problem has increased exponentially over the past few decades, with the prevalence of loneliness doubling (Jeste et al., 2020, p. 553).

Information technology has been developing and changing very rapidly. This situation affects many areas of life, especially work life. Thus, the Internet changes the way organisations conduct their activities by providing fast communication and access to and distribution of information, becoming an indispensable part of work life.

People live longer than ever and take part in work for longer periods. The increase in Internet use has changed how people work, what games they play, what they research and read, how they talk and how they conduct their personal relationships and communication-and it continues to change. Every day, people experience more and more connections digitally through social

+ Corresponding author 
media tools. However, despite these connections, loneliness increases and the negative consequences of loneliness increase. Loneliness occurs when a person subjectively feels that their relationships are inadequate. It can be considered a complex emotional sequence involving reactions to the absence of intimate and social needs. Although loneliness is temporary for some individuals, it can be a chronic condition for others (Ernst and Cacioppo, 1999, p. 1).

The Internet is a technological tool that creates significant development opportunities and increases employee productivity. The Internet has brought some positive and negative practices, behaviours, and consequences that coexist at the core of every change. As a matter of fact, using the Internet and the technology it supports, employees can avoid working. In other words, they can use the Internet during work hours for non-work-related purposes to avoid work or relieve boredom. This behaviour has been conceptualised in the current literature with the term cyberloafing, predominantly with a negative connotation. In its most general description, cyberloafing describes the use of the Internet by employees to access and send emails for non-workrelated purposes during work hours. This behaviour may also include behaviours and practices such as email jokes, browsing nonbusiness websites, online shopping, instant messaging, browsing newsgroups, and downloading music (RuningSawitri, 2012, pp. 320-321).

New workplaces created with technological developments showed great interest in the revolution of the way jobs are conducted and how they can increase the productivity and efficiency of the employees. However, the advent of technology has created new ways and opportunities for individuals to exhibit unusual and unknown behaviours. This study focuses on the relationship between cyberloafing behaviour and loneliness from a work-psychology perspective.

At this point, the aim of the study was determined to be predicting and evaluating the changes that may occur in work life in the time of COVID-19 on the basis of loneliness and cyberloafing. Common findings of secondary research were used in terms of work psychology. The studies in the literature on loneliness and cyberloafing address sociodemographics and some work-life factors. For this reason, sociodemographic factors such as gender, age, marital status, and income level and work-life factors such as personality, self-esteem, job performance, productivity, job satisfaction, health, Internet usage, stress, and burnout were discussed.

\section{WORK PSYCHOLOGY IN THE TIME OF COVID-19}

The study is influenced by many complex factors. Some of these relate to the individual and the psychological characteristics of the person, while others are communal, like social and cultural conditions. The relationship between the individual and the work is not limited to the individual's inner world and working conditions. The individual factors that give meaning to work for individuals are sociopsychological, such as the individual's feelings, thoughts, attitudes, and behaviours. Communal factors at the macro level are economic, political, and sociocultural. The meaning of work, with the complex effects of these factors, varies from person to person depending on individual variables such as the sociopsychological structure of the person, age, and gender. It can also differ between societies and between socioeconomic class, subculture, profession, and business groups within the same society (Çolak, 2018, p. 57).

In this context, work psychology mainly examines the thoughts, hopes, desires, needs, and fears that motivate people and determine the directions of their actions. Although desires and goals are hidden in behaviour, many other stimulating factors affect and direct the person's behaviour. In this sense, psychological factors contain many different elements, such as perception, motivation, learning, personality, and ego, that vary from individual to individual. These are generally shaped by environmental conditions, personal impressions, social environment, and the influence of culture. The factors in question, which differ depending on the individual, refer to the individual's psychological integrity of work.

COVID-19, which affects the whole world, continues to control employees, employers, and businesses. The pandemic has forced significant and radical changes in the way business is conducted in the work environment. The pandemic has brought an agenda of remote work, online meetings, recruitment or training -in other words, the transfer of almost all processes of the work environment-to digital platforms. As a result, digital transformation in work life has emerged as a strong impact of the pandemic. A new normalisation process has begun in the world, and a new work and society model that affects all areas has started to emerge.

Concepts such as loneliness, cyberloafing, digital mobbing, emotional resilience, psychological resilience, compassion, selfcompassion, conscious awareness, habits design, coping with loneliness, and coping with the crisis have gained importance (Hartman et al., 2020; Zoghbi-Manrique-de-Lara et al., 2019; Zessin et al., 2015; Neft \& Dahm, 2015).

The workplaces of the future will focus not on where and when work is done but on how it is done. Therefore, businesses will offer more new and innovative information technology to create the workplaces of the future by integrating technology and digital work into their processes. But digital work is more than using new and innovative information technology. Increasing flexibility in work life and blurring the boundaries between private and business life due to this flexibility results in the employee's desire for balance and structure (Dittes et al., 2019, p. 649). 
With the developments in technology, the continuous development, change, and transformation of work life (Wint, 2015, p. 1) causes employees to continue their work at an intense pace. Due to this intensity, employees are more worn out physically and mentally (Akın et al., 2017, p. 114). This leads to a deterioration of the balance of work and private life and an increase in stress on employees. On the other hand, the physical and mental stresses of employees also cause loss of motivation. Therefore, the employee's motivation is affected by psychological factors that are evaluated in the context of individual factors (Çolak, 2018, p. 59).

\section{LONELINESS}

A hundred and fifty years ago, loneliness was described by the poet Emily Dickinson as "fear that should not be explored but surrounded by darkness" (Achor et al., 2018). Loneliness, a phenomenon that every person can experience at any time in their life, does not discriminate between people. Psychiatrist Fromm-Reichmann (1959) raised awareness of loneliness and stated that a rigorous and scientific definition of loneliness was needed. In the following years, loneliness was defined primarily as a psychological condition, and efforts were made to measure individual differences. Peplau and Perlman (1979) expressed the concept of loneliness as "corresponding to the inconsistency between an individual's preference and actual social relationships." Weiss (1973) emphasised that this inconsistency leads to the negative experience of feeling lonely and/or the distress of feeling socially isolated, even among family or friends. With this definition, Weiss emphasised that both loneliness and feeling lonely do not necessarily mean being alone and that being alone does not necessarily mean feeling lonely. Indeed, one may feel lonely in a crowd or in a marriage, and one may even enjoy being alone from time to time to gain experiences of personal growth or take a temporary break from dealing with the demands of modern life (Peplau and Perlman, 1979, p. 102).

Loneliness can be felt at any time and by any person, although it is more likely in people and groups at risk of social alienation, isolation, and separation. In this context, loneliness can be observed prominently even in people surrounded by a large number of connections/followers/friends on social media, as well as a large number of young adults; it is not limited to elderly people who are upset and live alone. The trait of being alone is encountered throughout life. At this point, Köknel (1998) defined the concept of loneliness as a process that occurs as "modern people begin to suffer from loneliness, feel guilty because they are alienated from society and lose their psychological health by not being able to cope with the difficulties they face in life." According to Hall, loneliness is "an important indicator of the inability to meet the need to form a friendship or form a special relationship." According to Santrock (1993), loneliness was evaluated as "the inability to establish close interpersonal relationships" (Serin Bulut et al., 2010, p. 704). In the definition of Cacioppo et al. (2006), "it is a feeling that occurs when a person's basic and social needs are met at an inadequate level" (Wang and Dong, 2018, p. 1). In the definition of Fokkema et al. (2012, p. 205), loneliness is a subjective and negative experience, and this experience is the result of evaluating the match between the quantity and quality of existing relationships and the relationship desires or standards of the person. Some people with restricted social networks feel lonely, while others do not. Ponzetti defined loneliness as an interpersonal deficit that exists as a result of fewer or less satisfying personal relationships than a person desires. Jong-Gierveld says that loneliness involves not only having less satisfying relationships but also not having the opportunity to establish new relationships with others at a close level (Wang and Dong, 2018, p. 2). Loneliness is not just a feeling of being alone. In fact, people can be alone when they are not alone. This experience is much more than a temporary feeling; it is also a feeling that one's relationships lack meaning or depth. This feeling of loneliness arises when people do not have the quality or qualified social relationships to satisfy themselves in their lives (Oehler, 2017, p. 4).

Loneliness can be perceived as a social deficiency. It occurs in situations where a person's network of social relationships is smaller or less satisfying than the person wants and reflects the relationship between desired and achieved level of social interaction. The level of social communication a person desires is based on many considerations, including past levels of communication and their expectations for future social relationships. It can be experienced positively when low levels of social contact are desired. However, it is assumed that almost all people have recurring needs for social interaction with others (Peplau \& Perlman, 1979, pp. 101-2). Loneliness has three dimensions: private loneliness, relational loneliness, and collective loneliness. Each dimension also corresponds to different types of loneliness. Private loneliness, or what Weiss (1973) calls emotional loneliness, refers to the perceived absence of a person (e.g., a partner) who can rely on emotional support, provide mutual assistance, and acknowledge one's worth during any crisis. This dimension is defined by Dunbar as the inner core. It covers up to five people and corresponds to people we trust for emotional support during crises. Relational loneliness is called social loneliness by Weiss (1973). It means the perceived absence of quality friendships or family ties. Connections in the relational field are made with the "sympathy group." According to Dunbar, a "sympathy group" can include social friendships of 15 to 50 people. The relational space is limited to the multi-modal (visual, auditory, and tactile) area that allows face-toface communication and interactions. It is not the number of friends that matters, but the quality of friends/confidants. In the diagnosis of loneliness, this point is emphasised as very important. The third dimension that Weiss (1973) could not define in 
his qualitative studies is collective loneliness. It refers to a person's valued social identities, or "active network" (e.g., group, school, team, or national identity). This dimension, which Dunbar (2014) describes as the outermost social layer, includes between 150 and 1500 people ("active network") and corresponds to those who can provide low-cost support as well as weak ties (Cacioppo et al., 2015, pp. 241-42).

\section{CYBERLOAFING}

In production based on the misuse of the Internet, antiproductivity behaviours are becoming widespread with new shapes, definitions, and concepts with the diversity and prevalence of social media tools and the increasing prevalence of Internet access in every aspect of daily life. The inability to manage the virtual environment well makes it inevitable that organisations will experience significant and serious problems, especially in the process of creating new information (Whitty and Carr, 2006, pp. 235-250). Indeed, cyberloafing is one of the new behaviours and realities of work life based on the developments experienced. In the literature, cyberloafing, which is also conceptualised as cyberslacking or non-work-related computing or information systems misuse, is the most general expression of employees accessing the Internet for personal purposes during work hours or using email and Internet for private purposes during work hours (RuningSawitri, 2012, p. 321). According to Lim (2002, p. 675), cyberloafing is "the employee's use of the internet connection of the company during work hours and for personal needs." At the same time, cyberloafing is an inefficient use of time since it prevents employees from fulfilling and completing their main responsibilities, and given the aim of the study, it can be considered a deviant workplace activity. In the definition of Vitak et al. (2011, p. 1751), cyberloafing is expressed as nonwork Internet use during work hours, virtual deviance, personal Internet use at work, Internet abuse, recreational surfing in the workplace, and unnecessary computer use. In addition, it is claimed that cyberloafing cannot be considered completely harmful as it offers the individual creativity, flexibility, and a learning environment. According to Blanchard and Henle (2008, p. 1067), it is the personal use of email and the Internet in the workplace. Lim and Teo (2005, p. 1081) emphasised that the Internet has a significant impact on the business life and personal lives of people around the world, and they defined cyberloafing as "the action of employees who use their company's internet access for personal purposes during work hours." Beugre and Kim (2006, p. 834) described cyberloafing as a voluntary behaviour that causes harm to both the organization and its employees and violates organisational rules. The common point of the definitions related to cyberloafing is that the Internet is used for nonbusiness, personal purposes in the workplace (Blanchard and Henle, 2008, p. 1069). Cyberloafing behaviour, apart from the opportunities it offers, can also cause loss of productivity in business life. Online access has provided significant convenience to businesses, but it has also transformed businesses into places where employees intensively exhibit non-work-related behaviour during work hours (Whitty \& Carr, 2006, p. 237; Greenfield \& Davis, 2004, p. 348).

Many scientists conceptualize cyberloafing behaviour as just the traditional type of deviant behaviour in the workplace, while others consider this activity harmless or even productive (RuningSawitri, 2012, p. 321). Negative consequences caused by cyberloafing include loss of reputation, damage to privacy, infection by viruses and spyware in the organization's system, damage to organisational reliability, significant legal liability risks, delays in work, disciplinary punishment, and dismissal of employees (Malachowski, 2005, p. 1; Greenfield and Davis, 2004, p. 351).

Cyberloafing is classified differently. The classification made by Lim (2002, p. 691) is web browsing actions and email actions. The scope of this classification is defined as activities of browsing the sites for nonbusiness purposes (accessing sports-related news sites, downloading nonbusiness documents, etc.) and receiving, sending, and checking emails. Blanchard and Henle (2008, pp. 1069-1070) suggested that there are two types of cyberloafing: insignificant and serious. Insignificant cyberloafing includes behaviours such as surfing the internet, visiting news or sports websites, receiving and sending non-work-related emails, and online shopping. Employees think that this does not harm the organization, and such loafing is considered a natural situation. Serious cyberloafing includes actions such as following and playing on betting and gambling sites, visiting adult sites, and downloading music or programs without permission. Employees who engage in serious cyberloafing are aware of the danger of the situation and their legal responsibilities, but they cannot change their behaviour.

Mastrangelo et al. (2006, p. 735) grouped cyberloafing behaviours as inefficient/unproductive computer use and destructive/ destructive computer use. Inefficient cyberloafing behaviours are defined as online banking transactions, and harmful cyberloafing behaviours can be exemplified as performing illegal practices online. Cyberloafing has become the most common method for employees to waste their work hours. For this reason, this alarming use is the cause of increasingly intense unrest in work life (Sampat and Basu, 2017, p. 24). 
THE RELATIONSHIP BETWEEN LONELINESS AND CYBERLOAFING WITH SOCIODEMOGRAPHIC AND SOME WORK-LIFE FACTORS

When the studies on loneliness and cyberloafing were examined, it was seen that the concepts were discussed in terms of sociodemographic and work-life variables. Both concepts were examined in terms of common sociodemographic variables such as gender, age, marital status, and income level as well as common factors such as stress, burnout, conflict, exclusion, job satisfaction, and role ambiguity. Studies on the relationship between loneliness and cyberloafing are very limited.

With the COVID-19 pandemic, the changes in daily life and work routines affect some conceptual definitions. Processes related to loneliness and cyberloafing are among the multifaceted and deeply affected concepts. In this context, loneliness and cyberloafing, which were mainly evaluated concerning work life in the studies conducted before COVID-19, will come to the fore with the results of working remotely, based on the intertwining of work life with home life.

Since the new workspaces have evolved from houses that are our private living space, within the scope of the study, it has become necessary to evaluate the results of previous research on loneliness and cyberloafing in terms of both sociodemographic and some work-life variables. In this context, gender, age, marital status, income, and education level were evaluated within sociodemographic factors. Personality, job performance and productivity, job satisfaction, stress and Internet use were examined as some work-life factors.

\section{Relationship of Loneliness and Cyberloafing With Sociodemographic Factors}

In a study conducted with 249 students at the faculty of education of a private university in the Turkish Republic of Northern Cyprus (TRNC), gender was found to be an indicator of loneliness (Serin Bulut et al., 2010, p. 707). Another study found that women feel lonelier than men (Peplau and Perlman, 1979, pp. 104-105). In the study of Shankar et al. (2013, p. 163), loneliness is higher among women than men. Similarly, in another study, being a woman was found to be associated with loneliness (Pinquart and Sörensen, 2010, p. 245; Blom et al., 2020, p. 5). In the study conducted by Koç (2012, p. 3042), contrary to the general tendency, men stated that they felt lonelier than women. In another study conducted with 213 immigrants, no significant difference was found between the loneliness of immigrant women and immigrant men (Chan and Qiu, 2011, p. 1116). Berscheid and Walster (1974) stated that there is substantial evidence that physically attractive men and women are less loved and have more opportunities for social interaction than their less attractive peers. Therefore, they predicted that attractive people would be less likely to be alone (Peplau and Perlman, 1979, p. 104).

It is stated that Internet access has different effects on people by gender, and men have more Internet experience than women (Mastrangelo et al., 2006, p. 732). Male employees use the Internet more intensely than female employees and tend to use entertainment-oriented Internet sites (Garrett and Danziger, 2008, p. 291). In two different studies, males were found to have higher results than females in displaying cyberloafing behaviour, and the duration of cyberloafing was higher for males than females (Andreassen et al., 2014, p. 916; Niaei et al., 2014, p. 69). A similar result was obtained in a study conducted by Mamat and Baqutayan (2019, p. 30) with 95 people in Malaysia. In another study, respondents generally state that some form of cyberloafing at work is acceptable, and men in particular say it has a positive effect on the job (Lim and Chen, 2012, p. 343). In the studies conducted by Durak and Saritepeci (2019, p. 78) and Woods (2014, p. 41), cyberloafing behaviour of men was found higher than that of women. On the contrary, however, in a study conducted by El Din and Baddar (2019, p. 53) on nurses, women's cyberloafing was found to be higher than men (Durak 2020, p. 559). In the studies conducted by Askew et al. (2014, p. 514), no relationship was found between cyberloafing and gender.

In the relationship between age and loneliness, age was found to be negatively related to social interaction and positively related to cultural activities (Özdemir and Tuncay, 2008, pp. 3-4). In the study of Shankar et al. (2013, p. 163), a four-year longitudinal study was conducted with 6,034 participants with an average age of 65.5, and the relationship between age and Ioneliness was found to be positive. In the study conducted by Özdemir and Tuncay (2008, p. 1) with 721 university students aged between 18 and 25 , it was found that $60.2 \%$ of the sample experienced loneliness. In the study conducted with a total of 330 people aged 60 and over who visited a local health centre in Sinop due to various health problems, it was found that $49 \%$ of the people experienced moderate loneliness (Koç, 2012, pp. 3039-41). In the study conducted by Blom et al. (2020, p. 5) between the years 2000-2016, the loneliness of young people was found to be higher. This situation is defined as the result of the prevalence of social media use as well as the preference to live alone. In a study analysing whether older immigrant workers were more lonely than younger immigrants, no relationship was found between age and loneliness (Chan and Qiu, 2011, p. 1117).

Among the sociodemographic variables, the important effects of age on attitudes towards cyberloafing can be considered more acceptable for young employees. According to the research of Ahmad and Jamaluddin (2010, p. 10), this situation can 
be explained by technology and the tendencies of young people growing up in the age of technology and the Internet. Young workers who have grown up with computers appear to have more potential for Internet use than older workers (Mastrangelo et al., 2006, p. 732). Andreassen et al. (2014, p. 913) found a negative relationship between age and cyberloafing behaviour. When Hartijasti and Fathonah (2014, p. 11) evaluated three different generations, it was found that the Internet was used by the $\mathrm{Y}$ generation for both business and personal purposes during work hours, while the $\mathrm{X}$ generation and Baby Boomers used it only for business purposes during work hours. In a study examining individuals from the United States, Asia, and India and revealing the impact of demographic characteristics and work-related factors, it was revealed that cyberloafing is most likely in young managers. Based on further qualitative analysis, the pressure of their work forced them to look for stress relievers, and at this point, the Internet was an easy resource. Besides, the study stated that the high degree of autonomy of young managers enables them to maintain their cyberloafing tendencies (Ugrin et al., 2008, p. 75). A study examining the perceived prevalence and severity of various cyber-social activities with the participation of 226 working adults showed that perceived serious cyberloafing activities tend to be less common. It was also found that the Internet makes the boundary between work and home less clear. In addition, it was determined that the Internet makes it easier for work to enter the home and personal activities to enter work ( Lim and Teo, 2005, p. 1081). In a study conducted on nurses, it was found that those between the ages of 35 and 45 had higher cyberloafing behaviours compared to other age groups (El Din and Baddar, 2019, p. 53). In the studies by Mamat and Baqutayan (2019, p. 30), the cyberloafing behaviour of young employees was found to be higher than that of older employees. In the studies of Askew et al. (2014, p. 514) and Woods (2014, p. 4), no relationship was found between age and cyberloafing. Seventy-five studies conducted in Asia, Australia, Europe, and North America were subjected to meta-analysis to examine the sequence and development of loneliness throughout life, and it was observed that the sequence of loneliness is as stable as personality traits and follows an inverted U-shaped trajectory throughout life. It was found that loneliness decreases throughout childhood and remains basically constant from adolescence to the oldest period. Therefore, unlike other personality traits, changes in loneliness were generally considered unrelated to age (Mund et al., 2020, p. 24).

When evaluated in terms of marital status, loneliness is lower among married people. However, when the unmarried group is divided into more subgroups, loneliness is higher among widowed and divorced people than among singles, and loneliness doesn't differ from that of married people (Peplau and Perlman, 1979, pp. 104-105). A similar result was obtained from migrant workers in the study conducted by Chan and Qiu (2011, p. 1117). In the studies of Özdemir and Tuncay (2008, pp. 3-4) with university students, a significant relationship was found between romantic relationships and loneliness. Besides, the loneliness of students who did not have any romantic relationship and those who came from families whose parents were separated was found to be higher than the others. According to the study of Niaei et al. (2014, p. 69), in cyberloafing and marital status relationships, single employees display more cyberloafing behaviours than married ones. A similar result was found in the study of Örücü and Yıldız, 2014, p. 110).

In the study where the relationship between economic support needs, social interaction and loneliness showed a significant positive correlation; the loneliness of the participants who stated their needs for economic support and social interaction was found to be higher than the others (Özdemir and Tuncay, 2008, pp. 3-4). Similarly, in the studies of Pinquart and Sörensen (2010, p. 245), low socioeconomic status was found to be associated with increased loneliness.

In a study, it was concluded that as the income level increases, the frequency of personal Internet use during work increases (Garrett and Danziger, 2008, p. 291). On the other hand, according to the results of another study, the decrease in income levels causes an increase in serious cyberloafing behaviours (Örücü and Yıldız, 2014, p. 111).

Regarding the relationship between education and loneliness, a four-year longitudinal study with 6,034 participants with an average age of 65.5 determined that there is a relationship between higher education and loneliness. Similarly, in the studies of Achor et al., participants who had an educational level of at least a master's or doctoral degree and those that had a bachelor's degree were significantly different than those with a technical/associate degree (Shankar et al., 2013, p. 163). An opposite result was obtained in the studies of Blom et al. (2020, p. 8), and it was determined that individuals with low education levels experience more loneliness compared to individuals with higher education levels. Vitak et al. (2011, pp. 1-20) found a significant relationship with educational level in terms of cyberloafing diversity and individual cyberloafing behaviour in their research to determine the causes of cyberloafing. In terms of the frequency of cyberloafing, they found that there was no significant relationship with education level. In the studies conducted by Örücü and Yıldız (2014, p. 108), it is estimated that employees with high educational level generally engage in more insignificant cyberloafing activities.

\section{Relationship Between Loneliness and Cyberloafing and Some Work-Life Factors}

According to Buecker et al. (2020, p. 9), personality, which defines the relatively permanent patterns of cognition, emotion, and behaviour that distinguish individuals from each other, can influence individual perceptions of loneliness. The relationship 
between neuroticism and conscientiousness and loneliness as two personality traits was studied in 3,157 Chinese older adults in Chicago. One unit increase in neuroticism was associated with a 1.15 times greater likelihood of feeling lonely. One unit increase in conscientiousness results in a 3\% decrease in loneliness risk (Wang and Dong, 2018, p. 3). Few studies explicitly exploring the relationship between extraversion and loneliness have consistently found a negative relationship (Buecker et al., 2020 , p. 9). Regarding the relationship between conscientiousness and loneliness, the result was positive in some studies, negative in some studies, and had no relationship in others. A positive relationship was found in the few studies that directly investigated the relationship between neuroticism and loneliness. While the relationship between openness and loneliness was found negative in some studies, no relationship was found in some studies (Buecker et al., 2020, p. 10). In the studies of Buecker et al. (2020, p. 8), while extraversion, conformity, conscientiousness, and openness were negatively associated with loneliness, neuroticism was positively related. Data from 265 Romanian employees confirmed that extraversion predicts loneliness, which in turn affects job performance through burnout (Sîrbu \& Dumbravă, 2019, p. 7). Some results show that low self-esteem is associated with loneliness. Moore and Sermat (1974) stated that lonely individuals scored lower on self-esteem, self-realisation, and internal orientation subscales. Eddy (1961) found a significant relationship between both loneliness and an indirect self-measure and inconsistency in one's true and ideal self-concepts (Peplau and Perlman, 1979, p. 104).

In the survey study in Iran on the mutual relationship of personality traits of information workers and their tendency towards cyberloafing, it was concluded that neuroticism, extraversion, and openness had a positive effect on both types of cyber information (i.e., activities and behaviours), and intelligibility had a negative effect on cyberloafing behaviours (Sheikh et al., 2019). In the research (doctoral thesis) conducted by Phillips (2020, p. 76), a negative relationship was found between extroversion and cyberloafing, and when all other measured variables were kept constant, it was observed that cyberloafing behaviours decreased as extroversion increased.

In a study investigating the relationship between workplace loneliness and work performance, findings from 672 employees and 114 managers at the two organisations revealed that workplace loneliness is associated with low job performance. As mediators of this relationship, lonely employees have been identified as having lower accessibility and less affective commitment to their organisations (Özçelik and Barsade, 2018, p. 2343). A negative relationship was also found in a study evaluating the relationship between role performance and loneliness in a sample of teachers (Lam and Lau, 2012, p. 4276).

The Internet, which is used to get rid of work intensity and stress and to relax and empty the mind, is no longer unnecessary and now serves to increase employee productivity. For particular reasons, use of the Internet can allow a person to relax and experience an effect much like a break. Thus, it can help organisations reach their goals by meeting the psychological and social needs of the employees (Coker, 2011, p. 239). In a study conducted by Garrett and Danziger (2008, p. 287), it was concluded that as productivity increases, cyberloafing will also increase. Stanton (2002, p. 58) found that frequent Internet users are happier than those who use it less frequently. In another study whose sample was healthcare workers, it is concluded that messaging, gameplay, or other virtual behaviours pursued to avoid intense stress provide better performance during the day (McBride et al., 2015, p. 4). Instead of spending the whole workday tired and inefficient, it is very important for the employee to collect his energy at a point in the day to be able to do his job more effectively. At the same time, it is evaluated that he can get the highest job satisfaction and efficiency in this way (Lim, 2002, p. 692). In this context, results such as feeling happy, saving time, easy communication, and team building are among the positive aspects of cyberloafing (Chun and Bock, 2006, p. 1262). When the process is managed with a certain flexibility, it can contribute to employees doing work at home that they cannot complete in the business environment and even achieve more results thanf they could achieve in the workplace (Lim, 2002, p. 688). In a study conducted with human resources employees, a weak relationship was found between browsing behaviour and employee productivity (Mashal, 2017, p. 65). Lonely employees perform less well and quit more often, and they also feel less satisfied with their work. In the study carried out with 4,000 workers in the United States, lonely employees were reported to have lower job satisfaction, fewer promotions, and more frequent job changes and to be likely to quit their current jobs within the next six months (Achor et al., 2018). Within the scope of Cook's (2017, p. 125) doctoral thesis, a survey was conducted with 390 people through a questionnaire sent to those who wanted to answer from human resources managers and employees in their organisations. It was found that work productivity has a statistically significant and negative relationship with cyberloafing. Loneliness, an emotionally painful feeling, affects productivity at work with the characteristic of physical pain in the brain. Both Queen's University Smith School of Business and Gallup identified the excess costs created by loneliness as about 37\% more absenteeism, 49\% more accidents, 16\% lower profitability, and 65\% lower share price over time (Seppälä and King, 2017). In a study evaluating the relationship between loneliness and job satisfaction among teachers, a significant and negative correlation was found between the dimensions of loneliness in the workplace and teachers' job satisfaction (Tabancalı, 2016, p. 263; Zhou, 2018, p. 1014). A similar result was obtained in a study conducted with immigrant workers (Chan and Qiu, 2011, p. 1118). A study investigating the regulatory role of loneliness between job satisfaction and intention to leave work was 
conducted with 154 participants working in two different prisons in Bursa, Turkey. Loneliness was found to significantly mediate the relationship between job satisfaction and intention to leave work. At the same time, loneliness predicts the intention to leave work (Aytaç, 2015, p. 3-4). A practical study on job satisfaction and happiness of employees reveals that workplace loneliness is negatively associated with job satisfaction and job happiness and also has a negative correlation. As a contrary result, a study on the loneliness of migrant workers in China revealed that lonely workers have higher job satisfaction than other workers (Zhou, 2018, p. 1014).

In Cook's (2017, p.125) study conducted with 390 employees and a negative relationship was found between cyberloafing and job satisfaction. In another study conducted with 447 employees and 147 managers from various companies, cyberloafing on desktop computers was not found to be related to job satisfaction, but cyberloafing on mobile phones was negatively associated with job satisfaction (Askew, 2012, p. 41). In the study conducted within the scope of the doctoral thesis written by Phillips (2020, p. 76), no significant relationship was found between job satisfaction and cyberloafing behaviour in remote workers.

Two studies using cross-sectional designs investigated four possible mechanisms by which loneliness can cause harmful effects on health. These were health behaviours, cardiovascular activation, cortisol levels, and sleep. Total peripheral resistance was found to be higher in participants who were alone than in those who were not alone. Heart contraction, heart rate, and cardiac output were found to be higher in nonlonely participants than in lonely participants, and lonely individuals reported poorer sleep than nonlonely individuals (Cacioppo et al., 2002, p. 407). Loneliness is also important for managers, CFOs and CEOs. The last decade of research has shown that loneliness threatens not only our physical health and well-being but also our livelihood. It is also stated that loneliness has the same effect as 15 cigarettes a day in terms of health consequences and health costs (Achor et al., 2018). Research by Valtorta et al. (2016, p. 1009) shows that loneliness increases the risk of stroke by $29 \%$ and the risk of coronary heart disease (the leading cause of death in developed countries) by $32 \%$. Research by Sarah Pressman of the University of California, Irvine, shows that obesity reduces lifespan by $20 \%$, alcohol by $30 \%$,smoking by $50 \%$, and loneliness by $70 \%$ (Seppälä and King, 2017).

It was suggested that cyberloafing has positive effects in terms of relief from stress, burnout and boredom, creativity, having a good time, and increasing job satisfaction (Vitak et al., 2011, p. 11). In a study conducted with employees of a leading auto parts manufacturing company in Chennai, India, it was concluded that workplace burnout did not significantly affect cyberloafing. Another result in the same study is that exclusion in the workplace significantly affects cyberloafing behaviour (Gowrisankar and Vimala, 2019, p. 418). Similarly, a study whose survey data was collected from the online site Amazon Mechanical Turk found that workplace exclusion and emotional exhaustion had a significant positive association with cyberloafing (Koay, 2018, p. 1131). In another study, it was found that cyberloafing does not reduce work burnout, and there is a moderate relationship between role overload and cyberloafing (Stoddart, 2016, p. 63).

Loneliness is thought to play an important role in the development of Internet use and addiction and is still under investigation, with research continuing on the subject. In a meta-analysis of qualitative studies on Internet addiction conducted between 1996 and 2006, it was found that loneliness, together with isolation and low self-esteem is one of the main antecedents of Internet addiction. Current research supports this result (Pontes et al., 2014, p. 92). Regarding the relationship between Internet addiction and loneliness, in a study in Portugal with 131 students, relatively high Internet addiction was obtained at a rate of $13 \%$, and as a result of the correlation analysis, a relationship was found between loneliness, social loneliness, and variables related to the educational context. In addition, a group of $8.4 \%(\mathrm{~N}=11)$ stated that they were "seriously lonely" (Pontes et al., 2014, p. 95). In a study conducted with 96 online participants aged 18 to 72, it was found that Internet addicts are emotionally alone but not socially alone (Hardie and Tee, 2007, p. 44). Another study asked 158 adults questions about computer anxiety, loneliness, and the Internet. One of the results was that young, lonely, male participants stated that they used the Internet mainly for entertainment purposes (Matanda et al., 2004, p. 103). In a study conducted with 231 people from 93 families, children under the age of 10 and individuals who were not interested in Internet use in their families were not included. Increased use of the Internet has been associated with small but statistically significant decreases in intra-family communication and people's local social networks and an increase in loneliness, a psychological condition associated with social participation. More use of the Internet has also been found to be associated with increases in depression. It was observed that Internet use has statistical interaction with age. It is also found that increases in Internet use lead to greater increases in loneliness and social support for young people and is associated with a greater decline than adults (Kraut et al., 1998, p. 1028). Increased use of the Internet is also associated with increases in depression. In a longitudinal study conducted with 89 participants, it was stated that people use the Internet in various ways to fulfil their personal preferences. Extraversion and neuroticism were found as personality traits that were found to affect Internet use (Amichai-Hamburger and Ben-Artzi, 2003, p. 71). In a study on cyberloafing behaviour in companies with Internet access policies (82.6\%), surveys were conducted with 224 organisations on 
Internet abuse. In about $70 \%$ of the companies surveyed, more than half of the employees use the Internet at work. Despite the existence of Internet access policies, more than $60 \%$ of companies have discipline, and more than $30 \%$ of employees use the Internet inappropriately. Although accessing pornography, chatting online, playing games, investing, or shopping while at work business are the top reasons for disciplinary action or termination, many companies are not concerned about the seriousness of the problem (49.6\%) and/or they do very little to enforce Internet access policies (Greenfield and Davis, 2004, p. 347). In the research conducted by Woods (2014, pp. 42-43), whether companies' had or did not have Internet policies was not found to be related to cyberloafing. At the same time, the level of employees' knowing or not knowing the policies in their companies was not found to be related to cyberloafing. In many organisations, nonbusiness Internet browsing activities are not recommended. The study by Coker (2013, p. 114) suggests non-work-related Internet browsing behaviours replenish attention, just as relaxing formal/legal breaks do. The prediction was tested in two studies. The first is a controlled experiment, and the other is a nationwide survey. One of the results found non-work-related Internet use refocuses people's attention. The nationwide survey finds a correlation between workplace Internet browsing and perceived productivity (under 30 years) of those growing up in the Internet environment. In addition, differences in attitudes towards non-work-related Internet browsing were also found between older and younger workers.

\section{CONCLUSIONS}

COVID-19 has suddenly changed everyone's reality. Individuals, cities, economies, countries, and continents experienced the shock of lockdowns and the fear of uncertainty. Managers had to make a lot of decisions in a very short time about who should stay at work and who should go home, how and where people can move into the digital space, and what priorities are and how best to transfer those priorities to employees. In Ernst \& Young's 2019 survey of 500 board members and chief executive officers worldwide, only $20 \%$ of executives said they believe their company is ready to respond to major negative risk, and just a few months later, with the COVID-19 pandemic, their concerns were proven to be well founded. Global supply chain vulnerabilities and concerns over financial resilience highlighted concerns over strategic people and their ability to carry on during the COVID-19 pandemic; the COVID-19 outbreak has also been termed a "human-based crisis" (Caligiuri et al., 2020, p. 2).

The COVID-19 pandemic, which has turned into a global crisis, has caused radical changes and transformations in both social and business life. As businesses plan how to adapt to technology-based processes, the emerging global crisis has made it mandatory (rather than a choice) to transfer processes to digital platforms. Accordingly, ways of doing business and work life have changed, and the transition to flexible work models, especially to remote work, has begun. This transition happened quite suddenly, rather than gradually. This process has created the new normal in work life and has enabled employees to discuss new concepts and risks as well as to increase awareness of existing concepts and risks.

Since the COVID-19 outbreak, the future plans, predictions, and actions to be taken by many businesses have been renewed on the basis of risk analysis. It has become very important for business managers to be more solution-oriented than ever before and to manage the process as accurately and effectively as possible. Employees, who are an indispensable element of enterprises, have had to adapt to a complex and stressful working order filled with unknowns. The new risks associated with the environment of uncertainty are also an indicator of this. Transferring processes to digital platforms and applications to transition to flexible work models may adversely affect all processes and connections within the enterprise. Employees' need to cope with the crisis caused by COVID-19 causes them to experience higher stress levels day by day, to lose their motivation, to decrease their job satisfaction, to leave their jobs, and thus to become lonely.

As a matter of fact, the social distance and stay-at-home practices experienced during the COVID-19 process create a necessity for health gains, but they also appear to support the increase of cyberloafing and similar antiproductivity behaviours along with loneliness. In a study conducted with 74 people working in a hospital in Indonesia, a relationship between loneliness and cyberloafing was found that supports this information (Budiana, 2018, p. 84). Decisions that are implemented as solutions in every part of life and especially in business life can turn into problems over time, and every solution begins to exhibit problems. Both employers and employees need to get used to working remotely without the option of alternative workplaces (Carnevale et al., 2020). In this context, the transformation of houses from living space to workspaces also causes the boundaries between work and family to become more blurred day by day.

In the pre-COVID-19 world, the demand for technological control tools developed to combat the phenomenon called cyberloafing, which is the tendency of employees to use email and the Internet for personal purposes while at work, has increased sharply and intensely with the transition to home-work practices after COVID-19. With the pandemic, employers see technological tools as a way of minimising waste in a dynamic and uncertain economy to achieve corporate efficiency and performance by managing business and processes. In the post-COVID-19 world, investments in remote working technologies also seem to 
offer a ready-made, turnkey solution for companies that want to move production online and maintain the authority to closely monitor the activities of employees.

The creation of a technology-driven future with the process that emerged along with the pandemic and called the new normal will determine how we respond to a life crisis focused on central issues of life: what we believe; how we think; how we visualise our role in life; what our next generation core elements are; what emotions, thoughts, and behaviours we feel and exhibit; and what uncertainties about personal and corporate decisions can be resolved and what solutions implemented. The concepts of loneliness and cyberloafing, which have been evaluated in relation to different factors of both sociodemographic and work life, and whose mutual relations have been the subject of a very limited number of studies, will be studied more intensively concerning personal and organisational factors in the technology-intensive future. Studies whose subject is human will need a re-evaluation of the results with the capacity to create major results in minor changes. It will be possible to redefine the negativities before the new normal as positive behaviours. It may even be considered possible to present them as tools to prevent new life crises in gaining the habit of working remotely for institutions and employees.

\section{REFERENCES}

Achor, S., Kellerman, G. R., Reece, A., \& Robichaux, A. (2018). America's loneliest workers, according to research. Harvard Business Review. https://hbr.org/2018/03/americas-loneliest-workers-according-to-research

Ahmad, Z., \& Jamaluddin, H. (2010). Computer usage policy and employees' attitude towards cyberloafing. In proceeding Technology Innovation and Industrial Management 2010 Conference (TIIM 2010), 39-52.

Akın, A., Ulukök, E., \& Arar, T. (2017). İş-yaşam dengesi: Türkiye'de yapılan çalışmalara yönelik teorik bir inceleme. Afyon Kocatepe Üniversitesi Iktisadi ve Idari Bilimler Fakültesi Dergisi, 19(1), 113-124.

Amichai-Hamburger, Y., \& Ben-Artzi, E. (2003). Loneliness and internet use. Computers in Human Behavior, 19(1), 71-80. https://doi. org/10.1016/S0747-5632(02)00014-6

Andreassen, C. S., Torsheim, T., \& Pallesen, S. (2014). Predictors of use of social network sites at work - a specific type of cyberloafing. Journal of Computer-Mediated Communication, 19(2014), 906-921.

Askew, K. L. (2012). The relationship between cyberloafing and task performance and an examination of the theory of planned behavior as a model of cyberloafing [Doctoral dissertation, Department of Psychology, College of Arts and Sciences, University of South Florida]. Scholar Commons. http://scholarcommons.usf.edu/etd/3957

Askew, K., Buckner, J. E., Taing, M. U., Ilie, A., Bauer, J. A., \& Coovert, M. D. (2014). Explaining cyberloafing: The role of the theory of planned behavior. Computers in Human Behavior, 36, 510-519. http://dx.doi.org/10.1016/j.chb.2014.04.006

Aytaç, S. (2015). Loneliness as mediator between job satisfaction and intention to leave: A study on prison staff in Turkey. Arabian Journal of Business and Management Review, 5-6.

Berscheid, E., \& Walster, E. (1974). Physical attractiveness. Advances in Experimental Social Psychology, 7, 157-215.

Beugre, C. D. and Kim, D. (2006). "Cyberloafing: Vice or Virtue?" in Mehdi Khosrow-Pour-Ed.book, Emerging Trends and Challenges in Information Technology Management, 834-835.

Blanchard, A. L., \& Henle, C. A. (2008). Correlates of different forms of cyberloafing: The role of norms and external locus of control. Computers in Human Behavior, 24(3), 1067-1084. https://doi.org/10.1016/j.chb.2007.03.008

Blom, V., Kallings, L. V., Ekblom, B., Wallin, P., Andersson, G., Hemmingsson, E., Ekblom, Ö., Söderling, J., \& Bak, E. E. (2020). Self-reported general health, overall and work-related stress, loneliness, and sleeping problems in Swedish adults from 2000 to 2016 . International Journal of Environmental Research and Public Health, 17(511), 1-11. https://doi.org/10.3390/ijerph17020511

Budiana, F. A. (2018). Hubungan antara kesepian dengan perilaku cyberloafing pada karyawan, Skripsi Psikologi, Universitas Islam Negeri Sunan Ampel, Surabaya.

Buecker, S., Maes, M., Danissen, J. J. A., \& Luhmann, M. (2020). Loneliness and the big five personality traits: A meta-analysis. European Journal of Personality, 34, 8-28. https://doi.org/10.1002/per.2229

Cacioppo, J. T., Hawkley, L. C., Crawford, L. E., Ernst, J. M., Burleson, M. H., Kowalewski, R. B., William, B. M., Eve, V. C., \& Berntson, G. G. (2002). Loneliness and health: potential mechanisms. Psychosomatic Medicine, 64(3), 407-417.

Cacioppo, S., Grippo, A.J., London, S., Goossens, L., \& Cacioppo, J. T. (2015). Loneliness: Clinical import and interventions. Perspectives on Psychological Science, 10(2), 238-249. https://doi.org/10.1177/1745691615570616

Caligiuri, P., De Cieri, H., Minbaeva, D., Verbeke, A., \& Zimmermann, A. (2020). International HRM insights for navigating the COVID-19 pandemic: Implications for future research and practice. Journal of International Business Studies, 1-17. 
Carnevale, J. B. \& Hatak, I. (2020). Employee adjustment and well-being in the era of COVID-19: Implications for human resource management. Journal of Business Research, 116, 183-187. https://doi.org/10.1016/j.jbusres.2020.05.037

Chan, S. H., \& Qiu, H. H. (2011). Loneliness, job satisfaction, and organizational commitment of migrant workers: empirical evidence from China. The International Journal of Human Resource Management, 22(5), 1109-1127. https://doi.org/10.1080/09585192.2011.556785

Chun, Z. Y., \& Bock, G. (2006). Why employees do non-work-related computing: An investigation of factors affecting NWRC in a workplace. The Tenth Pacific Asia Conference on Information Systems (PACIS 2006), 1-16. http://aisel.aisnet.org/pacis2006/79

Coker, B. L. S. (2011). Freedom to surf: The positive effects of workplace internet leisure browsing. New Technology Work and Employment, 26(3), 238-247.

Coker, B. L. S.(2013). Workplace internet leisure browsing. Journal Human Performance, 26(2), 115-125. https://doi.org/10.1080/08959285. 2013.765878

Çolak, M. (2018). Çalışma kültürü. Kitapana Yayınevi.

Cook, A.W. (2017) Cyberloafing, job satisfaction, and employee productivity: A quantitative study. Doctor of Philosophy, Northcentral University School of Business and Technology Management.

Dittes, S., Richter, S., Richter, A., \& Smolnik, S. (2019). Toward the workplace of the future: How organizations can facilitate digital work. Business Horizons, 62(5), 649-661. https://doi.org/10.1016/j.bushor.2019.05.004

Dunbar, R. I. M. (2014). The social brain: Psychological underpinnings and implications for the structure of organizations. Current Directions in Psychological Science, 23, 109- 114. https://doi.org/10.1177/0963721413517118

Durak, H. Y. (2020). Cyberloafing in learning environments where online social networking sites are used as learning tools: antecedents and consequences. Journal of Educational Computing Research, 58(3), 539-569. https://doi.org/10.1177/0735633119867766

Durak, H. Y., \& Saritepeci, M. (2019). Occupational burnout and cyberloafing among teachers: Analysis of personality traits, individual and occupational status variables as predictors. The Social Science Journal, 56(1), 69-87. https://doi.org/10.1016/j.soscij.2018.10.011

Eddy, P.D. (1961). Loneliness: A discrepancy with the phenomenological self. Unpublished doctoral dissertation, Adelphi College, Garden City.

El Din, Y. K. Z., \& Baddar, F. M. (2019). Nurses' cyberloafing and its relationship to procrastination and conscientiousness in Damanhour National Medical Institute. American Journal of Nursing Science, 8(2), 48-58. http://doi.org/ 10.11648/j.ajns.20190802.13

Ernst, J. M., \& Cacioppo, J. T. (1999). Lonely hearts: Psychological perspectives on loneliness. Applied \& Preventive Psychology, 8(1), 1-22. https://doi.org/10.1016/S0962-1849(99)80008-0

Fokkema, T., De Jong Gierveld, J., \& Dykstra, P. A. (2012). Cross-national differences in older adult loneliness. The Journal of Psychology Interdisciplinary and Applied, 146(1-2), 201-228. https://doi.org/10.1080/00223980.2011.631612

Fromm-Reichmann, F. (1959). Loneliness. Psychiatry, Journal for the Study of Interpersonal Processes 22, 1-15.

Garrett, R. K., \& Danziger, J. N. (2008). On cyberslacking: workplace status and personal internet use at work. Cyberpsychology \& Behavior, 11(3), 287-292.

Gierveld, J. (1998). A review of loneliness: concept and definitions, determinants and consequences. Reviews in Clinical Gerontology, 8, 73-80.

Gowrisankar, M., \& Vimala, K. (2019). Antecedents of cyberloafing in automobile parts manufacturing industry: A descriptive study. Cikitusi Journal for Multidisciplinary Research, 6(4), 416-419.

Greenfield, D. N., \& Davis, R. A. (2004). Lost in cyberspace: The web @ work, CyberPsychology \& Behavior, 5(4), 347-353. https://doi. org/10.1089/109493102760275590

Hardie, E., \& Tee, M. Y. (2007). Excessive internet use: The role of personality, loneliness and social support networks in internet addiction. Australian Journal of Emerging Technologies and Society (AJETS), 5(1): 34-47.

Hartijasti, Y., \& Fathonah, Y. (2014). Cyberloafing across generation X and $Y$ in Indonesia. Journal of Information Technology Applications \& Management, 21(1), 1-16.

Hartmann, S., Weiss, M., Newman, A., \& Hoegl, M. (2020). Resilience in the workplace: A multilevel review and synthesis. Applied Psychology, 69(3), 913-959. https://doi.org/10.1111/apps.12191

Jeste, D. V., Lee, E. E., \& Cacioppo, S. (2020). Battling the modern behavioral epidemic of loneliness suggestions for research and interventions. JAMA Psychiatry, 77(6), 553-554. https://doi.org/10.1001/jamapsychiatry.2020.0027

Koay, K. Y. (2018). Workplace ostracism and cyberloafing: A moderated-mediation model. Internet Research, 28(4), 1122-1141. http://doi. org/10.1108/IntR-07-2017-0268

Koç, Z. (2012). "Determination of older people's level of loneliness. Journal of Clinical Nursing (JCN), 21, 3037-3046. http://doi.org/10.1111/ j.1365-2702.2012.04277.x

Köknel, Ö. (1998). Kaygıdan Mutluluğa Kişilik. İstanbul: Altın Kitaplar Yayınevi.

Kraut, R., Patterson, M., Lundmark, V., Kiesler, S., Mukophadhyay, T., \& Scherlis, W. (1998). Internet paradox: A social technology that reduces social involvement and psychological well-being? American Psychologist, 53(9), 1017-1031. 
Lam, L. W., \& Lau, D. C. (2012). Feeling lonely at work: Investigating the consequences of unsatisfactory workplace relationships. The International Journal of Human Resource Management, 23(20), 4265-4282. http://dx.doi.org/10.1080/09585192.2012.665070.

Lim, V. K. G. (2002). The IT way of loafing on the job: Cyberloafing, neutralizing and, organizational justice. Journal of Organizational Behavior, 23, 675-694.

Lim, V. K. G., \& Chen, D. J. Q. (2012). Cyberloafing at the workplace: Gain or drain on work? Journal of Behaviour \& Information Technology, 31(4), 343-353. https://doi.org/10.1080/ 01449290903353054

Lim, V. K. G., \& Teo, T. S. H. T. (2005). Prevalence, perceived seriousness, justification and regulation of cyberloafing in Singapore: An exploratory study. Information \& Management, 42(8), 1081-1093. https://doi.org/10.1016/j.im.2004.12.002

Malachowski, D. (2005). Wasted time at work costing companies billions. https://apexassisting.com/wasted-time-at-work-costing-companiesbillions/ 24.09.2020.

Mamat, N. B., \& Baqutayan, S. M. (2019). Differential perspectives of cyberloafing activities about computer ethics among employee. JOSTIP, 5(1), 22-33.

Mashal, H. (2017). Uncontrolled workplace breaks and productivity [Doctoral study]. College of Management and Technology, Walden University. Matanda, M., Jenvey, V. B., \& Philips, J. G. (2004). Internet use in adulthood: Loneliness, computer anxiety and education. Behaviour Change, 21(2), 103-114.

Mastrangelo, P. M., Everton, W., \& Jolton, J. A. (2006). Personal use of work computers: Distraction versus destruction. Cyberpsychology \& Behavior, 9(6), 730-741.

McBride, D., LeVasseur, S. A., \& Li, D. (2015). Nursing Performance and Mobile Phone Use: Are Nurses Aware of Their Performance Decrements?. JMIR human factors, 2(1), e6. https://doi.org/10.2196/humanfactors.4070

Moore, J. A., \& Sermat, V. (1974). Relationship between self-actualization and self-reported loneliness. Canadian Counsellor, 8(3), 194-196.

Mund, M., Freuding, M. M., Möbius, K., Horn, N., \& Neyer, F. J. (2020). The stability and change of loneliness across the life span: A meta-analysis of longitudinal studies. Personality and Social Psychology Review, 24(1), 24-52. DOI: 10.1177/1088868319850738.

Neff, K. D., \& Dahm, K. A. (2015). Self-compassion: What it is, what it does, and how it relates to mindfulness. In B. D. Ostafin, M. D. Robinson, \& B. P. Meier (Eds.), Handbook of mindfulness and self-regulation (p. 121-137). Springer Science + Business Media. https://doi. org/10.1007/978-1-4939-2263-5_10

Niaei, M., Peidaei, M. N., \& Nasiripour, A. A. (2014). The relation between staff cyberloafing and organizatıonal commitment in organization of environmental protection. Kuwait Chapter of Arabian Journal of Business and Management Review, 3(7), 59-71.

Oehler, A. N. (2017). Loneliness, meaning in life, and depressive symptomology in college students [College thesis]. Sally McDonnell Barksdale Honors, Oxford.

Örücü, E., \& Yıldız, H. (2014). İşyerinde kişisel internet ve teknoloji kullanımı: Sanal kaytarma. Ege Akademik Bakış, 14(1), 99-114.

Özçelik, H., \& Barsade, S. G. (2018). No employee an island: Workplace loneliness and job performance. Academy of Management Journal, 61(6), 2343-2366. https://doi.org/10.5465/amj.2015.1066

Özdemir, U., \& Tuncay, T. (2008). Correlates of loneliness among university students. Child and Adolescent Psychiatry and Mental Health, 2(29), 1-6.

Peplau, L. A., \& Perlman, D. (1979). Blueprint for a social psychological theory of loneliness. In M. Cook \& G. Wilson (Eds.), Love and attraction (pp. 99-108). Pergamon.

Phillips, R. (2020). Age, sex, and personality as predictors of job satisfaction and cyberslacking in an all remote workforce. Doctoral thesis, Capella University.

Pinquart, M., \& Sörensen, S. (2010). Influences on loneliness in older adults: A meta-analysis. Basic and Applied Social Psychology, 23(4), 245-266.

Pontes, H. M., Griffiths, M. D., \& Patrão, I. M. (2014). Internet addiction and loneliness among children and adolescents in the education setting: An empirical pilot study. Aloma, 32(1), 91-98.

Ponzetti, J.J. \& Cate, R.M. (1980). The relationship of personal attributes and friendship variables in predicting loneliness. Journal of College Student Development, 29, 292-298.

RuningSawitri, H. S. (2012). Role of internet experience in moderating influence of work stressor on cyberloafing. Procedia - Social and Behavioral Sciences, 57, 320-324. http://doi.org/10.1016/j.sbspro.2012.09.1192

Sampat, B., \& Basu, P. A. (2017). Cyberloafing: The di(sguised)gital way of loafing on the job. The IUP Journal of Organizational Behavior, 16(1), 19-37.

Santrock, J. W. (1993). Adolescence An Introduction. Brown and Benmarck Pub. Wisconsin.

Seppälä, E., \& King, M. (2017, June 29). Burnout at work isn't just about exhaustion. It's also about loneliness. Harvard Business Review. https://hbr.org/2017/06/burnout-at-work-isnt-just-about-exhaustion-its-also-about-loneliness 
Serin Bulut, N., Aydınoğlu, N., \& Aysan, F. (2010). Examining the predictors of loneliness levels of university students. Procedia Social and Behavioral Sciences, 9, 704-708. http://doi.org/10.1016/j.sbspro.2010.12.221

Shankar, A., Hamer, M., McMunn, A., \& Steptoe, A. (2013). Social isolation and loneliness: Relationships with cognitive function during 4 years of follow-up in the English longitudinal study of ageing. Psychosomatic Medicine, 75, 161-170. https://doi.org/10.1037/hea0000437

Sheikh, A., Aghaz, A., \& Mohammadi, M. (2019). Cyberloafing and personality traits: An investigation among knowledge-workers across the Iranian knowledge-intensive sectors. Journal of Behaviour \& Information Technology, 38(12), 1213-1224. https://doi.org/10.1080/014492 9X.2019.1580311

Sîrbu, A. A., \& Dumbravă, A. C. (2019). Loneliness at work and job performance: The role of burnout and extraversion. Psihologia Resurselor Umane, 17(7), 7-17. https://www.hrp-journal.com/index.php/pru/article/view/298

Stanton, J. M. (2002). Company profile of the frequent internet user. Communications of the ACM, 45(1), 55-59.

Stoddart, S. R. (2016). The impact of cyberloafing and mindfulness on employee burnout. [Doctoral dissertation, Detroit, Michigan]. Wayne State University Dissertations. Paper 1487. https://digitalcommons.wayne.edu/oa_dissertations/

Tabancalı, E. (2016). The relationship between teachers' job satisfaction and loneliness at the workplace. Eurasian Journal of Educational Research, 66, 263-280. https://files.eric.ed.gov/fulltext/EJ1149164.pdf

Ugrin, J. C., Pearson, J. M., \& Odom, M. D. (2008). Profiling cyber-slackers in the workplace: Demographic, cultural, and workplace factors. Journal of Internet Commerce, 3(6), 75-89. https://doi.org/10.1300/J179v06n03_04

Valtorta, N. K., Kanaan, M., Gilbody, S., Ronzi, S., \& Hanratty, B. (2016). Loneliness and social isolation as risk factors for coronary heart disease and stroke: systematic review and meta-analysis of longitudinal observational studies. Heart, 102, 1009-1016. https://doi.org/10.1136/ heartjnl-2015-308790

Vitak, J., Crouse, J., \& LaRose, R. (2011). Personal internet use at work: Understanding cyberslacking. Computers in Human Behavior, 27(5), 1751-1759. https://doi.org/10.1016/j.chb.2011.03.002

Wang, B., \& Dong, X. Q. (2018). The Association between personality and loneliness: Findings from a community-dwelling Chinese aging population. Gerontology \& Geriatric Medicine, 4, 1-9. http://doi.org/10.1177/2333721418778181

Weiss, R. S. (1973). Loneliness: The experience of emotional and social isolation. Cambridge, MA: MIT Press.

Whitty, M. T., \& Carr, A. N. (2006). New rules in the workplace: Applying object-relations theory to explain problem internet and email behaviour in the workplace. Computers in Human Behavior, 22(2), 235-250.

Wint, S. H. (2015). Comparison of motivational orientation preferences of traditional and virtual workplace employees (Publication No. 3721115) [Doctoral dissertation, Capella University]. ProQuest Dissertations Publishing.

Woods, F. (2014). A study into the relationship between cyberloafing, procrastination and conscientiousness in the workplace. https://esource. dbs.ie/handle/10788/2074, 24.09.2020.

Zessin, U., Dickhäuser, O., \& Garbade, S. (2015). The relationship between self-compassion and well-being: A meta-analysis. Applied Psychology: Health and Well-Being, 7(3), 340-364. https://doi.org/10.1111/aphw.12051

Zhou, X. (2018). A review of researches workplace loneliness. Psychology, 9, 1005-1022. http://doi.org/10.4236/psych.2018.95064

Zoghbi-Manrique-de-Lara, P., Viera-Armas, M., \& García, G. D. B. (2019). Does supervisors' mindfulness keep employees from engaging in cyberloafing out of compassion at work?. Personnel Review. https://doi.org/10.1108/PR-12-2017-0384 